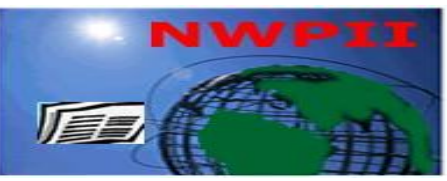

American Journal of Biomedical Sciences

ISSN: 1937-9080

nwpii.com/ajbms

\title{
Malnutrition and Cardiometabolic Risk among Turkish Adolescents: a Public Health Concern during Epidemiological Transition
}

\author{
Aleksandra S. Kristo ${ }^{1}$ and Angelos K. Sikalidis ${ }^{1, *}$ \\ ${ }^{1}$ Department of Nutrition and Dietetics, Yeni Yuzyil University Istanbul, Istanbul, Turkey \\ *Corresponding author: \\ Dr. Angelos Sikalidis \\ Yeni Yuzyil University Istanbul \\ Yilanli Ayasma Caddesi No. 26 \\ 34010 Istanbul, Turkey \\ Tel: +90-212-444-5001 \\ Fax: +90-212-481-4058 \\ E-mail: as545@cornell.edu
}

Received: 25 October 2014; | Revised: 23 November 2014; | Accepted: 23 December 2014

\begin{abstract}
Cardiovascular disease (CVD) is a chronic disease prevalent both in developing and developed countries. Numerous CVD risk factors associated with nutritional behavior and status in children and adolescents set the stage for adult CVD. A significant body of evidence suggests that there is opportunity for abolishment of at least some of the adverse manifestations of CVD and ability for health improvement if proper nutritional practice is followed during young age. Turkey is a country with a large overall population of which a significant part is children and adolescents. Moreover, Turkey is in epidemiological transition exhibiting health and nutritional issues of both the developing and the developed world, with more than half of all deaths in Turkey related to CVD. Furthermore, Turkey is a country of significant and unusual diversity in terms of geography, socio-economic status and origin among others. However, there are not many studies assessing the cardiometabolic risk in adolescent and the ones that assess a few risk factors of CVD are localized in certain areas. In this work we gather, organize and compare the results of several studies on the topic and reach certain conclusions as per the current condition of adolescents in Turkey in regards to malnutrition and cardiometabolic risk.
\end{abstract}

Keywords: Adolescent, Public Health, Nutrition, Obesity, Underweight.

\section{Introduction}

Cardiovascular disease (CVD) constitutes the primary cause of morbidity in the developed countries, generating a considerable financial burden if combined with the ensuing disability and mortality [1]. Interestingly, CVD events have become the leading cause of death in developing countries as well [1]. The World Health 
Organization (WHO) has underlined that "there are no geographic, socioeconomic or gender boundaries in terms of CVD" [2]. In this context, CVD is indeed a leading cause of death globally, considering both developing and developed countries [2]. Developing countries undergoing epidemiological transition are particular prone to increased incidence of CVD since economic development, urbanization, industrialization and a series of societal changes reflecting Westernization extend secondary changes in dietary habits, exercise and lifestyle in general, thus modifying risk for a series of chronic diseases including CVD. Several identified risk factors affect the overall CVD risk including demographic characteristics, family history of CVD, cigarette smoking, physical inactivity, abnormal serum lipids and lipoproteins, increased body weight (obesity), hypertension, insulin resistance and type 2 diabetes mellitus, vitamin D status, polycystic ovaries syndrome (PCOS) and mineral status especially for Fe, Se and I [2,3]. Low birth weight, folate deficiency and infections are newly emerging risk factors particularly frequent among the poorest segments of the general population in low- and middle-income countries (developing countries) [4]. Over $80 \%$ of worldwide CVD deaths occur in low- and middle-income countries, at similar rates between genders and often during productive age. The disproportionate death rate in the developing countries can be attributed to inadequate financial resources, limited number of professionals with expertise in prevention or management of CVD, less access to healthcare services and higher exposure to risk factors such as tobacco [4].

There is a strong nutritional component determining the overall CVD risk with prospective and retrospective studies demonstrating that CVD risk factors such as obesity, lipid profile, unhealthy diets and inactive lifestyle that begin early-on establish trends, habits and an overall lifestyle usually maintained throughout adulthood [5-8]. There is clear evidence associating abdominal adiposity, the metabolic syndrome (MS) and CVD [9]. Additionally, MS in obese children and adolescents is a serious public health issue globally [10]. Since dietary habits and patterns are shaped and established at younger ages, while chronic diseases such as CVD "incubate" for years only to be manifested during adulthood, monitoring and delineating nutrition factors affecting cardiometabolic risk emerges as a powerful prevention tool and public health strategy, especially when targeting adolescent populations that will become the future subject of the healthcare systems in a few decades.

It is widely accepted that the underlying causes and factors for the development of atherosclerosis and other circulatory conditions exert their detrimental effects from an early age. Mounting evidence suggests that poor diet and inadequate physical activity during childhood are associated with subclinical atherosclerosis and its progression in adulthood. Contrastingly, healthy dietary patterns during childhood, such as ones including adequate intake of vegetables, fruits and polyunsaturated fatty acids, are associated with lower CVD risk in adulthood [11, 12]. In general, eating patterns can exert a significant effect on healthy growth and development (positive or negative) during childhood and adolescence and subsequently on adulthood health status [5]. Therefore, providing nutritional education and information to young populations, creating environments of good nutritional habits and securing access to safe, good quality, nutritious, healthy foods is critical for optimizing health and nutritional status, while reducing risk for chronic diseases during the lifespan [13].

Turkey has an overall population of $73,722,988$ according to the latest available census data (2010 census) of which $50.2 \%$ is males and $49.8 \%$ females. The median age of the population in Turkey is 29.2 while median age is 28.7 for males and 29.8 for females. From the total population: $25.6 \%$ belongs to the $0-14$ yearold age group, $67.2 \%$ belongs to the 15-64 yearold age group and $7.2 \%$ to the $>65$ year-old age group. The proportion of population living in Istanbul (most populous city in Turkey) is $18 \%$ $(13,255,685$ persons). This metropolitan area is followed by Ankara (the capital) with $6.5 \%$ (4,771,716 persons), Izmir with $5.4 \%(3,948,848$ persons), Bursa with $3.5 \%$ (2,605,495 persons) and Adana with $2.8 \%$ (2,085,225 persons), respectively. While $76.3 \%$ of the total population 
$(56,222,356$ persons) live in the province and district centers (urban population), $23.7 \%$
$(17,500,632$ persons) live in small size towns and villages (rural population) (Fig.1A) [14].
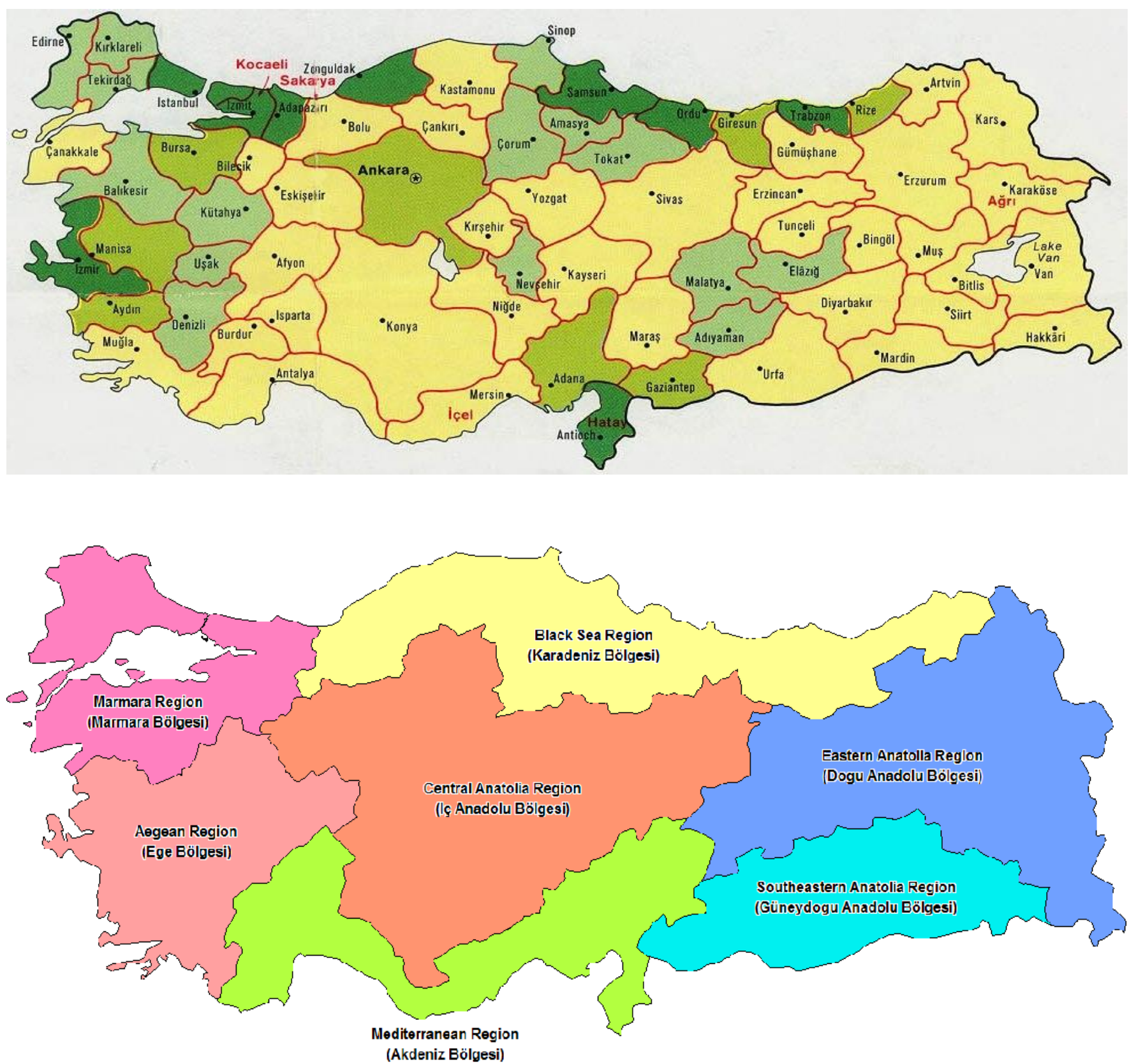

Figure 1. A) The map shows the administrative divisions of the Turkish state with their capitals and main cities. The darker the green color, the larger the population density of the province. B) The map depicts in color-coded fashion the 7 regions of the Turkish state.

Turkey is a middle-income country undergoing epidemiological transition and Westernization [1], and with a significant proportion of young population. In this context, Turkey can constitute a good example for studying the relation between a dynamically changing nutritional status and health status determinants such as CVD risk factors in adolescent populations. Turkey has experienced rapid urbanization and industrialization in the 
past few decades while receiving influences from both Europe and Asia due to its geographical location between the two continents. Following the global trends in cardiovascular risk transition Turkey has seen over the last twenty years a marked increase in urbanization, income and Western diet prevalence, associated with an increase in the body mass index (BMI) and fasting plasma glucose values for both males and females [1]. With respect to nutritional status, Turkey is facing problems of a developing and developed country simultaneously. The nutritional status of the Turkish general population varies significantly exhibiting a high heterogeneity directed by several parameters such as regional geography, socio-economic status (SES), urban-rural settlement, inequality of income, and lack of nutrition education among others [15].

In Turkey, nutritional education is limited and of debatable effectiveness as it lacks practical components such as cooking lessons, while the overall curriculum and time assigned to the subject are rather inconsiderable. Further, there is limited number of trained nutritionists and dietitians in the country considering the overall population due to limited and only recently created higher education programs producing nutrition graduates. Eating patterns in Turkey are particularly diverse following a heterogeneous population distributed in various geographical locations of the country. In this context, while for example the coastal regions of Turkey demonstrate more of a Mediterranean-diet eating pattern, the central and southeastern regions constituting the majority of the country exhibit eating patterns mainly based on cereals, pastry and red meat rather than fruits and vegetables [16]. Nonetheless, according to Food and Agriculture Organization (FAO) Food Balance Sheets, the general population in Turkey appears to be generally well nourished (FAOSTAT, 1999). However, available data indicate that both obesity and CVD are common problems among Turkish adults [15]. In this regard understanding the nutritional behavior and status of adolescents and the relevant trends in relation to risk factors for chronic disease such as weight and metabolic profile, are key for better public health outcomes in the future. For the present review, studies were selected from PubMed using relevant keywords supplemented by manual search from the reference list of identified papers. The studies had to be utilizing/reporting data within the last 15 years in order to reflect the current situation in Turkey to the most accurate degree possible.

\section{Nutritional landscape in Turkey in relation to CVD risk}

The average Turkish diet seems to meet the recommended daily intake for energy and most nutrients, but not animal protein, calcium, vitamin A or riboflavin. Additionally, micronutrient deficiencies such as iron deficiency anemia and iodine deficiency disorders constitute a major problem of undernutrition particularly among mothers, women of childbearing age as well as schoolchildren [15]. Nevertheless, dietrelated chronic disease such as obesity, CVD, type 2 diabetes mellitus and hypertension among others are also prevalent in Turkey [15]. An increasing consumption of animal food products and a reduction in total cereal intake has been reported since the 1980's as a result of increased food availability, including Western-type foods, along with the rapid social and economic transition [17], with public health efforts obviously lagging behind in this respect.

For instance, the need to improve nutrition education of Turkish population by increasing consumer use and interest in food label nutrition information was demonstrated by a multiple-site survey on food and nutrition labeling that included 26 regions of Turkey [18]. Among the 96 participating adolescents (12-17 year olds who purchased food for themselves at least twice weekly), $39.6 \%$ never checked the nutrition facts label, $43.7 \%$ checked sometimes and $16.7 \%$ checked frequently, while no participant reported to always check the label [18]. Even among those who have been checking the nutrition label however it is unclear what the level of their nutrition knowledge is and how useful the information they derive is in terms of improving their food choices. Lack of knowledge or unwillingness to take into consideration nutrition data about the food consumed, increases the 
possibility for poor food choices (eg. highly processed, highly energy dense) which may well lead to risk factors associated with induced risk for CVD (eg. sodium intake-associated blood pressure increase, sub-optimal lipid profile due to increased intake of saturated and trans fat, obesity due to excessive energy intake). In this context, the study indicates the necessity for nutrition education in the young population, in addition to access and availability of nutrition information as tools for controlling risk for CVD and/or other chronic diseases by establishing good dietary practices.

Eating habits such as skipping breakfast or excessive intake of carbohydrate-rich foods (candy, desserts, soft drinks) in Turkish adolescents have been reported for the last 30 years, in addition to low intakes $(<67 \%$ of Recommended Daily Allowance) of energy, protein, vitamins $\mathrm{A}$ and $\mathrm{C}$, riboflavin, iron and calcium in both male and female adolescents [19].

Compared to American Heart Association (AHA) recommendations, Turkish adolescents were reported to have a higher fiber, but also total fat, saturated fatty acid, cholesterol and sodium intake [20].

Prospective studies following-up young individuals into adulthood have indicated the association between youth diet and adult CVD, among other modifiable risk factors [21].

Less healthy eating patterns characterized by overconsumption of refined carbohydrate (rye, potatoes) and fat (butter, sausages, milk) were associated with higher carotid intima-media thickness in adulthood. On the contrary, vegetable and fruit-rich diets are likely to protect against preclinical adult CVD [21].

The recent dietary habits and nutrition status of adolescent populations in Turkey have been assessed by several regional studies conducted over the last decade (Table 1) [17, 22-27].

According to the United States Department of Agriculture (USDA) Healthy Eating Index (HEI)-2005 and based on a single 24-hour dietary recall, no subjects with "a good diet" were identified in a population of over 1,000 adolescents between 14 and 18 years in Turkey's capital, Ankara. A "poor diet" or a "diet that needs improvement" was estimated for $42.8 \%$ and $57.2 \%$ of adolescents, respectively [27]. Low whole grain, but high total grain, low meat and beans, inadequate dairy product consumption and less than five servings of fruits and vegetables per day reduced the total HEI-2005 score significantly. This is a clear indication that the eating habits of Turkish adolescent may well contribute to the increase of chronic disease risk including CVD if they persist through adulthood. Higher fat-derived energy and lower fiber levels (a dietary practice associated with higher CVD risk), differentiated the "poor" and "needs improvement" diet groups. In addition, $25.6 \%$ of adolescents were reported to skip main meal(s), whereas the majority consumed three main meals and one to four snacks per day [27].

In another cohort of 10-14 year old adolescents ( 890 total: 464 boys and 426 girls) in Ankara the diet quality was assessed by the Mediterranean Diet Quality Index (KIDMED). Among the participants a $59.2 \%$ majority had a mid-quality/needs-improvement diet, $22.9 \%$ had an optimal diet quality and a $17.9 \%$ of the participants had a low quality diet. The educational level of the mother was observed to positively affect the KIDMED score, while the low diet quality was related with low levels of nutritional knowledge [26]. The participants scored low in knowledge pertaining to vegetable, fruit and low-fat food consumption, as well as optimal eating times and portions. Girls were more knowledgeable about the benefits of vegetable consumption, while boys had better knowledge on fish, chicken, veal, and mutton consumption, possibly related to Turkish male preference for meat and meat-based foods, along with a dislike for vegetables [26]. Adhering to a Mediterranean eating pattern from early-on, is associated with reduced arterial stiffness in young adulthood, further supporting the value of healthful diets in cardiovascular prevention. On the other hand, eating habits similar to the ones observed in the above cohorts may not be conducive to long-term cardiovascular health [21]. 
Table 1. Adolescent dietary profile and body weight in various regions of Turkey

\begin{tabular}{|c|c|c|c|c|c|c|c|c|c|c|c|}
\hline \multirow[t]{3}{*}{ Study } & \multicolumn{8}{|c|}{ Subject Characteristics } & \multirow{3}{*}{$\begin{array}{c}\text { Dietary } \\
\text { Assessment } \\
\text { Approach }\end{array}$} & \multirow[t]{3}{*}{ Main Findings } & \multirow[t]{3}{*}{ Region } \\
\hline & \multirow[t]{2}{*}{$\mathbf{n}$} & \multirow[t]{2}{*}{ M } & \multirow[t]{2}{*}{$\mathbf{F}$} & \multirow[t]{2}{*}{ Age (y) } & \multicolumn{4}{|c|}{ BW categories (\%) } & & & \\
\hline & & & & & UW & NW & OW & Ob & & & \\
\hline [23] & 1044 & 516 & 528 & $12-13$ & 12 & 74.1 & 11.9 & 2 & 3-day 24-h recall & $\begin{array}{l}\text { Higher TG, TC and LDL-C in } \\
\text { OW/Ob males; higher TG and } \\
\text { lower HDL-C in OW/Ob female; } \\
\text { Energy under-reporting among } \\
\text { males. }\end{array}$ & $\begin{array}{l}\text { Istanbul, } \\
\text { Ankara, } \\
\text { Izmir }\end{array}$ \\
\hline [17] & 2258 & 1137 & 1121 & $15-20$ & 25.7 & 69.9 & 4.4 & 0.6 & $\begin{array}{c}\text { Eating \& Drinking } \\
\text { 29-item } \\
\text { Questionniare }\end{array}$ & $\begin{array}{l}22.2 \% \text { always had milk or juice at } \\
\text { breakfast; having breakfast was } \\
\text { protective against obesity. Higher } \\
\text { SES, male gender and fast food } \\
\text { preference were predictors of } \\
\text { overweight or obesity. }\end{array}$ & Eskisehir \\
\hline [24] & 737 & 397 & 340 & $11-14 / 15$ & $\mathrm{n} / \mathrm{a}$ & $\mathrm{n} / \mathrm{a}$ & $\begin{array}{l}\text { U: } 12.8 ; \\
\text { R: } 7.3\end{array}$ & $\begin{array}{l}\text { U: } 8.4 ; \\
\text { R: } 4.3\end{array}$ & $\begin{array}{l}\text { Dietary Habit } \\
\text { Questionnaire }\end{array}$ & $\begin{array}{l}\text { Higher income (M) associated with } \\
\text { fast food consumption; Larger } \\
\text { family size (NM) decreased OW } \\
\text { and Ob risk. }\end{array}$ & $\begin{array}{c}\text { Meltem (U), } \\
\text { Kepez (R) }\end{array}$ \\
\hline [25] & 625 & 310 & 315 & $11-15$ & $\mathrm{n} / \mathrm{a}$ & $\mathrm{n} / \mathrm{a}$ & 10.2 & 8.3 & $\begin{array}{l}\text { Food Guide } \\
\text { Pyramid }\end{array}$ & $\begin{array}{l}1.9 \% \text { met all the recommendations } \\
\text { of the Food Guide Pyramid; } 23.4 \% \\
\text { consuming at least } 3 \text { food groups } \\
\text { as recommended. }\end{array}$ & Istanbul \\
\hline [26] & 890 & 464 & 426 & $10-14$ & $\mathrm{n} / \mathrm{a}$ & $\mathrm{n} / \mathrm{a}$ & $\mathrm{n} / \mathrm{a}$ & $\mathrm{n} / \mathrm{a}$ & KIDMED & $\begin{array}{l}59.2 \% \text { mid-quality/needs- } \\
\text { improvement diet; } 22.9 \% \text { optimal } \\
\text { diet quality; } 17.9 \% \text { low quality diet. }\end{array}$ & Ankara \\
\hline
\end{tabular}

\section{Dietary habits, body weight and CVD risk in adolescents}

Several studies indicate the relationship between poor eating habits and abnormal body weight and CVD risk factors in Turkish adolescent populations. A cross sectional survey of 625 participants, 11-15 year old students (boys and girls) in the city of Istanbul, documented a very low (1.9\%) participant compliance to the Food Guide Pyramid (FGP). In fact only $23.4 \%$ of the children reported to consume at least three food groups as per the recommendations, in agreement with findings of US-based studies [25]. Limited and/or poor adherence to FGP is frequently associated with dietary schemes and habits, which induce risk of obesity and chronic disease including CVD [11, 12]. Although the female, overweight and obese participants $(50.5 \%, 10.2 \%$ and $8.3 \%$ of the cohort, respectively) seem to have better knowledge of the FGP recommendations, their food group consumption did not differ significantly from their peers [25], indicating that knowledge alone does not suffice to ensure good diet practices. Fat recommendations were met by $27 \%$, while fruit and vegetable recommendation only by $15 \%$ of the cohort. In addition, daily fast food consumption was reported by $31 \%$, meal skipping by $60.8 \%$, while daily breakfast consumption by $51 \%$ of the participants [25]. 
What is more, overweight/obesity was much lower than underweight among a cohort of 2,258 students (1,137 boys and 1,121 girls) between 15 and 20 years of age in Eskisehir (Western Turkey). A $69.9 \%$ majority was found to have a normal weight, $25.7 \%$ were underweight, and only $4.4 \%$ were overweight or obese students, with obesity at $0.6 \%$ [17].

Always having milk or juice at breakfast was reported by $22.2 \%$ of the students, with breakfast consumption reported as protective against obesity. Contrastingly, a higher socioeconomic level, being a male and fast food preference were predictors of overweight or obesity. According to the study authors, being underweight could be attributed to not having enough food. However, a higher underweight prevalence among girls, $68.1 \%$ compared to $31.9 \%$ in boys, could be related to body image perception [17].

In another survey in Eskisehir with 1,044 students of 11-14 years from 9 different schools with relative social uniformity, $83.1 \%$ were normal weight, $11.8 \%$ were underweight, mostly male, and $4.9 \%$ overweight including only one obese boy. While boys had lower mean BMI values for every age group, gender effect on the BMI values across the age groups was not significant. Gender did not differentiate eating attitude in many items of the eating and drinking questionnaire used in the study, although girls obtained higher scores for healthy habits in 18 out of 29 items and had significantly higher scores only for whole-wheat bread preference and weight-control behaviors such as increasing exercising or reducing food consumption to prevent weight gain. Most of the students reported eating meals together with their family (83.0\%), having breakfast $(77.9 \%)$, consuming daily meat, milk, or eggs $(70.2 \%)$ and at least one portion of vegetables, fruit or salad $(68.2 \%)$, not adding salt without tasting meals first $(71.9 \%)$, and finishing the food presented on their plate $(54.4 \%)$ [22].

In a study including a total of 737 students between 11 and 14-15 years, of metropolitan $(44.8 \%)$ and non-metropolitan $(55.2 \%)$ residence, obesity and overweight prevalence was higher in the metropolitan area compared to nonmetropolitan area; obesity $8.4 \%$ compared to 4.3
$\%$, and overweight $12.8 \%$ compared to $7.3 \%$, respectively. Contrastingly, normal and underweight prevalence was lower in the metropolitan area compared to non-metropolitan area; normal $77.4 \%$ compared to $82.7 \%$, and underweight $1.5 \%$ compared to $5.8 \%$, respectively.

The majority of students from both backgrounds reported to have breakfast at home. The metropolitan students did not usually have lunch at home, but at school canteens or nearby restaurants (called "lokanta" in Turkey) and generally consumed more snacks, whereas most non-metropolitan students had both breakfast and lunch at home. A higher income in the metropolitan area was associated with higher fast food consumption, while a larger family size in the non-metropolitan area seemed to decrease the risk of overweight and obesity and subsequent CVD [24].

In a separate study, most of the 1,044 randomly selected adolescents (12-13 years old; 516 males and 528 females) from urban areas of Istanbul, Ankara and Izmir (the three largest cities in Turkey) were shown to be of normal weight $(74.1 \%)$, while underweight and obesity co-occurred at similar rates, $12 \%$ and $11.9 \%$ respectively and only $2 \%$ of this population was obese. Interestingly, overweight and obese boys were shown to under-report their energy and macronutrient intake to such extend that significant differences in these parameters emerged compared to the normal weight participants [23]. Compared to their normal weight counterparts, the overweight males had significantly higher triglycerides, total cholesterol (C) and low-density lipoprotein cholesterol (LDL-C), while the overweight females had higher triglycerides and lower high-density lipoprotein cholesterol (HDL-C), all recognized risk factors for CVD development [23].

Of note, the estimated low overweight and obesity prevalence in Turkish adolescents is concurrent with a weight-control behavior among girls demonstrating dieting and exercise behavior consistent to a desire to be thinner [22]. Irregular eating patterns, desire to be thin and concerns for weight gain, have all been reported in various regional studies. Interestingly, self-reporting was 
indicated as a limiting factor in several of the included studies also pointing to the fact that often times participants were either adopting "apologetic" attitudes towards their food choices and amounts consumed, or showing low levels of nutritional literacy. High fruit and vegetable consumption, while desirable in the context of heart-healthy eating, is used as a dieting strategy among Turkish female adolescents [28].

Along with focusing on a healthy weight, eating habits during childhood and adolescence require special consideration. Unhealthy dietary habits developed and established during this critical period require special attention regardless of the current weight. For instance, lean BMI children that grow to be obese adults seem to be susceptible to metabolic syndrome, especially with regards to high blood pressure [29]. Overall, diet can function as a powerful tool to favorably modify a series of risk factors that occur earlier than asymptomatic adult CVD. While avoiding risk factors while at a young age is the optimal approach, opportunities for intervention seemingly still exist under compromised cardiovascular health in order to reverse the condition and salvage a healthier phenotype [21].

\section{Body weight and CVD risk factors in the adolescents of Turkey}

\subsection{Cardiometabolic risk in Turkey from childhood to adulthood}

On a global scale childhood obesity has increased profoundly over the last decade. According to 2010 data, there are approximately 43 million overweight children under the age of 5 years old with 35 million (a staggering 81\%) living in developing countries [30]. There is a strong association between excess body weight when underage and manifestation of obesity during adulthood. More specifically, 90\% of obese individuals during adolescence are predicted to become obese adults, while $75 \%$ of 12 -year old obese will grow to be obese adults $[30,31]$. Further, at least $41 \%$ of 7 -year old obese are expected to be obese during adulthood and one fourth of obese pre-school children will also be obese as adults [31]. The adult population in Turkey is characterized by significant prevalence of obesity, CVD, type 2 diabetes mellitus and hypertension among other diet-related chronic diseases [15]. According to a 2012 WHO report [32], $74 \%$ of all years of life lost in Turkey are attributed to non-communicable diseases (particularly of metabolic/nutritional nature), while the respective European figure is $80 \%$ [32]. Obesity prevalence in Turkish adults over the age of 20 years is higher than that of Europe for both males and females (WHO data Table 2) (WHO compares Turkey to Regional Average and considers Turkey for comparison purposes as part of the European region). A study titled "Have Healthy Diets Protect Your Heart' conducted by the Turkish Ministry of Health [33] reported that in 15,468 individuals over 30 years old, obesity prevalence was $21 \%$ for males and $41.5 \%$ for females.

In addition to overweight and obesity, a considerable overall risk of cardiovascular disease is indicated in the Turkish population by several lines of evidence. A growing trend in central adiposity, combined with an impaired protection and high atherogenicity due to a combination of genetically low HDL-C (typically $10-15 \mathrm{mg} / \mathrm{dl}$ less compared to the populations of the USA and Western Europe) with usual LDL-C levels [34], and lifestyle factors such as inactivity and smoking rather prevalent among Turks, generate a major disadvantage for this population regarding CVD occurrence and overall health [35-38].

Other researchers have indicated that despite their lower BMI compared to American adolescents, Turkish adolescents demonstrate elevated triglycerides; $26.7 \%$ versus $25.5 \%$ for white Americans, $10.5 \%$ for African Americans and $24.7 \%$ for Hispanic Americans [39]. The same study also reported significantly lower HDL-C levels for Turkish adolescents; $13.4 \%$ compared to $26.1 \%$ for white Americans $11.7 \%$ for African Americans and 20.2\% for Hispanic Americans. In the adult population the observations are similar since Turkish adults are known to exhibit lower HDL cholesterol and higher triglycerides compared to Westerners even at lower BMIs [39]. 
4.2 Obesity among children and adolescents, a state inducing CVD risk

While it is not entirely clear to what extend childhood obesity directly causes adult CVD, similar to other lifestyle factors it tends to persist over time undermining the overall health of individuals [40]. Over the previous two decades childhood obesity in Turkey increased from 6-
$7 \%$ to $15-16 \%$ [33]. In Turkey there are studies performed at the local level covering various geographical regions of the country [41-59]. A summary and a comparison of the results of available studies on adolescent obesity are shown on Table 2.

\begin{tabular}{|c|c|c|c|c|c|c|c|}
\hline \multirow[t]{2}{*}{$\mathbf{n}$} & \multirow{2}{*}{$\begin{array}{l}\text { Age } \\
\text { (yrs) }\end{array}$} & \multicolumn{2}{|c|}{$\begin{array}{c}\text { Obesity } \\
\text { Prevalence (\%) }\end{array}$} & \multirow[t]{2}{*}{ Author } & \multirow[t]{2}{*}{ Year } & \multirow[t]{2}{*}{ Location $^{1}$} & \multirow[t]{2}{*}{ Population ${ }^{2,3}$} \\
\hline & & Female & Male & & & & \\
\hline 4,120 & $6-17$ & 7.3 & 4.0 & Sancak R et al. & 1999 & Samsun & 635,254 \\
\hline 5,795 & $6-14$ & 1.5 & 1.8 & Akis $\mathrm{N}$ et al. & 2003 & Bursa & $1,630,940^{*}$ \\
\hline 715 & $6-15$ & 4.4 & 4.3 & Gozu A et al. & 2007 & Mardin & 82,444 \\
\hline 850 & $6-15$ & 1.4 & 1.4 & Semiz S et al. & 2008 & Denizli & 620,093 \\
\hline 1,179 & $6-15$ & 6.6 & 7.6 & Suzek $\mathrm{H}$ et al. & 2010 & Mugla & 350,050 \\
\hline 3,460 & $\begin{array}{l}6-15 \\
11-\end{array}$ & 9.05 & 11.97 & Battaloglu Inac et al. & 2012 & Mardin & 86,948 \\
\hline 8,848 & 18 & 7.0 & 8.4 & Ercan $S$ et al. & 2012 & Ankara & $4,842,136$ \\
\hline $\mathbf{n}$ & $\begin{array}{c}\text { Age } \\
\text { (yrs) }\end{array}$ & \multicolumn{2}{|c|}{$\begin{array}{l}\text { Total Obesity } \\
\text { Prevalence (\%) }\end{array}$} & Author & Year & Location ${ }^{1}$ & Population ${ }^{2,3}$ \\
\hline 1,311 & $3-18$ & \multicolumn{2}{|c|}{4.3} & Turan $S$ et al. & 2001 & Istanbul & $9,085,599^{*}$ \\
\hline 3,703 & $\begin{array}{l}6-17 \\
12-\end{array}$ & \multicolumn{2}{|c|}{1.6} & Krassas et al. & 2004 & Kayseri & $732,354^{*}$ \\
\hline 989 & $\begin{array}{l}17 \\
10-\end{array}$ & \multicolumn{2}{|c|}{1.9} & Oner $\mathrm{N}$ et al. & 2004 & Edirne & $119,298^{*}$ \\
\hline 1,647 & 16 & \multirow{2}{*}{\multicolumn{2}{|c|}{$\begin{array}{l}3.6 \\
4.8\end{array}$}} & Uckun-Kitapci A et al. & 2004 & Ankara & $3,540,522^{*}$ \\
\hline 1,510 & $6-17$ & & & Simsek F et al. & 2005 & Ankara & $3,540,522^{*}$ \\
\hline 1,044 & $6-17$ & \multicolumn{2}{|c|}{2.0} & Sur $\mathrm{H}$ et al. & 2005 & $\begin{array}{l}\text { Istanbul } \\
\text { Ankara } \\
\text { Izmir }\end{array}$ & $\begin{array}{l}9,085,599^{*} \\
3,540,522^{*}\end{array}$ \\
\hline 2,465 & $6-17$ & \multicolumn{2}{|c|}{3.6} & Turkkahraman D et al. & 2006 & Antalya & $603,190^{*}$ \\
\hline 6,924 & $6-17$ & \multicolumn{2}{|c|}{6.1} & Simsek E et al. & 2008 & Bolu & 120,001 \\
\hline 5,368 & $6-12$ & \multirow{2}{*}{\multicolumn{2}{|c|}{7.8}} & Saglam H et al. & 2008 & Bursa & 220,4874 \\
\hline 11,629 & $2-15$ & & & Kalkan Ucar S et al. & 2009 & Izmir & $2,727,968$ \\
\hline 924 & $\begin{array}{l}6-16 \\
10-\end{array}$ & \multicolumn{2}{|c|}{$\begin{array}{l}0.5 \\
3.7\end{array}$} & Discigil G et al. & 2009 & Aydin & 573,884 \\
\hline 2,491 & 19 & \multicolumn{2}{|c|}{6.8} & Cizmecioglu $\mathrm{F}$ et al. & 2009 & Kocaeli & $1,422,752$ \\
\hline 9,048 & $6-18$ & \multirow{2}{*}{\multicolumn{2}{|c|}{$\begin{array}{l}2.2 \\
1.6\end{array}$}} & Yuca AS et al. & 2010 & Van & 539,619 \\
\hline 3,600 & $6-11$ & & & Pirincci E et al. & 2010 & Elazig & 331,479 \\
\hline
\end{tabular}

Across the included studies, the obesity rate in adolescence ranges for girls from 1.4 to $9.05 \%$ and for boys from 1.4 to $11.97 \%$. In a study conducted in 1,510 adolescent participants aged 6-17 years an average obesity rate of $4.8 \%$ was observed regardless of gender. In the area of 
Samsun at a sample of 4,120 participants aged 617 years the obesity rates were $7.3 \%$ for females and $4.0 \%$ for males, while in Mugla the respective values from a 1,179 sample were $6.6 \%$ for females and $7.6 \%$ form males (age range 6-15 years). In 715 adolescent from Mardin $4.4 \%$ of females and $4.3 \%$ of males were obese, whereas another study from the same area with 3,460 participants demonstrated obesity rates at $9.1 \%$ for females and $12 \%$ for males. Contrastingly, in a 5,795 cohort from Bursa (6-14 years old) the respective obesity rates were only $1.5 \%$ and $1.8 \%$. Similar rates were observed for subjects from Denizli (although the sample size was smaller reaching 850 participants), where the obesity rates were $1.4 \%$ for both females and males. Finally, in a cohort of 1,044 adolescents (age range 6-17) in three major cities in Turkey (Istanbul, Ankara and Izmir) the obesity rate was only $2 \%$ for both females and males. However, in another study by Ercan and colleagues [59] with a much larger sample, albeit of different age rage (8,848 participants aged 11-18) in Ankara the rates of obesity were $8.4 \%$ for females and $7.0 \%$ for males. In the same study approximately $10.6 \%$ of females and $6.1 \%$ of males were found to be overweight (Table 2). Overall obesity prevalence ranges from 1.6 to $7.8 \%$ in the included studies of children and adolescents. Adolescent obesity in particular was reported for $1.9,3.6$ and $6.8 \%$ of the adolescent participants in Edirne, Ankara and Kocaeli, respectively [49-50, 55]. An interesting observation from all the aforementioned studies is that there is a significant range regarding the rates of obesity even when the same area is considered. For instance, Ankara where one study reports for females an obesity rate of $2 \%$, while another $8.4 \%$ (Table 2). There are several potential reasons to explain such a remarkable difference in the obesity rate prevalence from different studies. Besides the considerable difference in the sample size, there is a notable difference in the geographical representation of the studies. As it can be deducted from Figures $1 \mathrm{~A}$ and $1 \mathrm{~B}$, the areas covered by the studies available, constitute a limited, partial and scattered geographical selection as far as areas and populations are concerned. Although certainly indicative, the study samples are not necessarily highly representative of the overall population in Turkey. Another important factor that may be strongly contributing to the difference in obesity prevalence rates is the time difference in terms of when the studies were conducted. The studies discussed herein span over the last 15 years a time period in which one can definitely see the results of changing/shifting paradigms in terms of dietary patterns and habits particularly in a country undergoing rapid urbanization and Westernization, as is the case with Turkey. Nonetheless, despite the fluctuation regarding obesity rates overall, there is a clear trend of increase for the rate of obesity for both males and females over the years. Further, for the ages under 18 years, there is no significant difference in the obesity rate between males and females (in fact males seem to be at a higher rate compared to females). However, in the adult population women are much more obese than men [32-33]. Another factor potentially contributing to different rates of obesity includes different age ranges for some studies.

Given the fact that there is no central/national study or monitoring effort regarding the issue of adolescent obesity in Turkey, and the fact that there are only a few studies with varying sample sizes on the subject, it becomes challenging to decipher what a reasonably accurate assessment of obesity's magnitude among Turkish adolescent is. Clearly, there is significant diversity in Turkey in a variety of factors that could determine obesity and malnutrition such as access to food, urban vs. rural setting or socio-economic status. Even though the overall, adolescent obesity rates in Turkey do not appear particularly high based on the limited data available, according to the WHO data, the obesity rate for adults in Turkey is definitely high, reaching $22.8 \%$ for men and $35.6 \%$ for women (Table 3) [32-33].

\subsection{Co-occurrence of overweight/obesity with underweight}

An interesting fact about Turkish adolescent nutritional status derives from the rates of underweight. A study by Oner and colleagues [49] assessed 989 adolescents aged 12-17 from 
Edirne selected in a systematically random manner from each school of Edirne center and reported that $11.1 \%$ of girls were underweight, $10.6 \%$ overweight and $2.1 \%$ obese. On the other hand, boys exhibited $14.4 \%$ underweight, $11.3 \%$ overweight and $1.6 \%$ obesity. Given the limitations of geography and sample size, these results are indicative but not necessarily representative of Turkey as a whole. However, within the study's population, the underweight prevalence is similar with overweight/obese prevalence in both genders, an interesting finding also reported by other researchers [49].

Table 3. Obesity and overweight prevalence (\%) in Turkey according to national and international sources

\begin{tabular}{lcccccccc}
\hline & $\begin{array}{l}\text { General Population } \\
\text { Turkish Ministry of } \\
\text { Health, 2010* }[33]\end{array}$ & $\begin{array}{c}\text { Age 6-18 years } \\
\text { Turkish Ministry of } \\
\text { Health, 2010* [33] }\end{array}$ & $\begin{array}{c}\text { Age 18+ years } \\
\text { Turkish Ministry of } \\
\text { Health, 2010* [33] }\end{array}$ & $\begin{array}{c}\text { Age 20+ years } \\
\text { Turkey - Health } \\
\text { Profile, WHO 2010 } \\
{[4]}\end{array}$ \\
\hline Male & Female & Male & Female & Male & Female & Male & $\begin{array}{c}\text { Femal } \\
\text { e }\end{array}$ \\
\hline Obese & $12.3 \%$ & $18.5 \%$ & $9.1 \%$ & $7.3 \%$ & $20.5 \%$ & $35.7 \%$ & $22.8 \%$ & $35.6 \%$ \\
Overweight & $36.9 \%$ & $27.4 \%$ & $14.2 \%$ & $14.4 \%$ & $39.1 \%$ & $29.7 \%$ & n/a & n/a \\
\hline
\end{tabular}

- WHO, World Health Organization; n/a, non available.

- NB: For comparison purposes, WHO considers Turkey as part of the European Region.

*Statistics reported by the Turkish Ministry of Health pertain to 12 major areas of Turkey and are not nation-wide.

The latest national report by the Directorate General of the Republic of Turkey Ministry of Health Office of Studies [60], released in 2014, illustrates that among males and females aged 618 approximately $15 \%$ is underweight whereas another approximately $5 \%$ is severely underweight. In the same report, an average of $14 \%$ and $8 \%$ of females is overweight and obese respectively, while $14 \%$ and $10 \%$ of males are overweight and obese respectively. Performing a different read of the data, only about half of the adolescent population regardless of their gender is at normal BMI. This illustrates that both underweight and obesity are equally problematic conditions in the case of Turkish adolescent further supporting the notion that Turkey is in nutritional transition unlike the West (Europe and North America) where nutritional status problems are primarily obesity-related.

Studies in Turkey have underlined the oddity of underweight and obesity coexistence among Turkish adolescent.

\subsection{Social parameters leading to obesity and impacting CVD risk}

A study by Manios et al. [61] investigated the relationship between socioeconomic status and cardiovascular risk factors (energy intake, weight, HDL, LDL, total cholesterol, triglycerides) in 510 randomly selected schoolchildren aged 12-13 years old (257 boys and 253 girls) from Istanbul. While obesity and underweight status co-occurred in this group, interestingly enough for adolescents of higher socioeconomic background higher energy intake, higher rates of obesity and unhealthy blood lipid profile (lower HDL-C/total C, higher LDL/total C and higher total triglycerides) were observed. The authors conclude that higher socioeconomic status in fact is associated with higher obesity and the related cardiovascular disease risk for adolescents [61].

Similar observations have been reported by another study that assessed obesity rates among 1,348 participants (age 6-16) to conclude that higher socioeconomic status is positively associated with obesity in Turkish adolescent [54].

Another study conducted with 1,044 schoolchildren from three cities in Turkey, Istanbul 
$(n=510)$, Izmir $(n=245)$ and Ankara $(n=289)$ aged 12 and 13 years, assessed the relationship between paternal and maternal level of education and cardiovascular risk factors [62]. The authors report that higher level of parental education is associated with adverse blood lipid profile and energy intake, suggesting higher risk for cardiovascular disease [62]. This trend of inverse correlation of socio-economic status and adolescent health status in Turkey, was previously observed by another study in two groups of 225 students. Compared to the lower socio-economic status exhibiting $8 \%$ overweight and obesity, the incidence of overweight and obesity of adolescents from higher socioeconomic status was significantly higher reaching $22 \%$ [63].

\subsection{Physiological parameters impacting CVD risk}

In a sample of 592 children aged between 6 and 14 years who were examined in general pediatrics clinics of Istanbul, 32\% of children were characterized as obese according to BMI reference values for Turkish children. The daily energy intake between obese and non-obese was similar, while performing physical activity was reported by $6 \%$ of obese and $40.9 \%$ of non-obese children. Adolescent obesity was strongly associated with parental obesity, especially on the mother and her family, as well as out of home working mother [64].

In a 1,346 adolescent cohort (15-18 years) in Manisa, Western Turkey, approximately $3.5 \%$ of the participants were hypertensive (systolic and/or diastolic blood pressure $\geq 95^{\text {th }}$ percentile for sex, age and height). Being at risk of overweight or overweight, $10.7 \%$ and $3.2 \%$, respectively, was positively associated with hypertension, suggesting that low hypertension risk may be attributed to the low overweight prevalence among these adolescents [65]. Similar results were observed in another cohort of 1,020 students (593 males and 427 females, age 14-18) in Sivas, a Middle Anatolian province where hypertension was prevalent at $4.4 \%$ of the students. A significant correlation was observed between prevalence of hypertension and BMI, but not other variables (smoking, age, gender, and family history of diabetes) [66].

\subsection{Time-dependent trends of CVD risks}

There seems to be a trend towards increasing obesity for children and adolescents as defined by changes of BMI over time. Significant changes were observed in Turkish children anthropometric and blood pressure characteristic between 1990 and 2005 [67]. In 2005 higher weight, height and BMI. During the same 15-year period and according to international criteria, obesity prevalence increased from 0.7 to $3.4 \%$, and overweight from 4.2 to $15.8 \%$ of the children [67].

Atabek and colleagues [68] assessed the change in the prevalence of MS of 202 obese adolescents (aged $7-18$ years) in an urban area of Turkey (Konya) over 5 years from 2006 to 2011. Notably, according to this study the rate of MS doubled over 5 years moving from $27.2 \%$ for pre-adolescent and $37.6 \%$ for post-adolescent to $56.4 \%$ and $63.3 \%$ respectively, with increased rates of morbidity and adverse lipid profiles.

Agirbasli et al. followed the population trends of blood pressure, BMI, lipids and fasting glucose among adolescent aged 8-18 [69]. Two different cross-sectional studies, one in 1989 $(n=1,385)$ and one in $2008(n=1,746)$ assessed BMI, HDL-C, triglycerides, blood pressure and fasting glucose levels. The authors concluded that there was a significant increase in BMI and high blood pressure while the metabolic syndrome occurrence doubled over the last two decades [69].

\section{Additional malnutrition factors}

Apart from low energy intake and the associated underweight as discussed above, poor eating habits of Turkish adolescents are further indicated by several micronutrient deficiencies. Iron deficiency and iron-deficiency anemia have been reported in several areas in Turkey (Istanbul, Ankara, Izmir, Denizli, Edirne). When iron status was assessed in the combined Istanbul-Ankara-Izmir cohort of 1,014 adolescents (after excluding those unsuitable for iron status assessment due to recent acute illness or inflammation), serum ferritin levels indicating 
iron deficiency $(<15 \mu \mathrm{g} / \mathrm{l})$ were detected in $19.1 \%$ of all the participants: $17.5 \%$ of the 504 males and $20.8 \%$ of the 510 females. A higher prevalence of iron deficiency was observed in males and females of low SES in both males and females, although significantly different from medium and high SES only among males. Compared to medium and high SES, low SES males reported lower consumption of red meat, fish and citrus fruits, along with higher tea consumption. The overall $19.1 \%$ prevalence of iron deficiency was concurrent with an overall $3.9 \%$ iron deficiency anemia (hemoglobin, $\mathrm{Hgb}<$ $12 \mathrm{~g} / \mathrm{dl}$ ), which did not differ significantly among the SES groups and between genders. Interestingly, a $14.1 \%$ prevalence of overweight and obesity was estimated for the same population [70].

The overall prevalence of anemia in 1,120 children in Denizli, 672 girls and 448 boys aged 12 to 16 years, was $5.6 \%$; $8.3 \%$ of the girls and $1.6 \%$ of the boys exhibited anemia $(\mathrm{Hgb}<12 \mathrm{~g} / \mathrm{dl}$ and $<13 \mathrm{~g} / \mathrm{dl}$, respectively). Iron-deficiency anemia was diagnosed in $59 \%$ of anemic participants, combined iron and vitamin $\mathrm{B}_{12}$ deficiency anemia in $41 \%$ anemic participants, while no folic acid deficiency was found. Family socio-economic status, regional traditional eating habits, irregular eating and concerns for gaining weight were important factors in the development of adolescent anemia in this population [71].

In a less recent study, serum folic acid levels were found to be deficient for $16.3 \%$, marginal for $46 \%$ and adequate for $37.6 \%$ of an adolescent cohort of 704 girls between 12-17 years in the Edirne area. Compared to the participants with normal folic acid level, the deficient participants reported lower intakes of folic acid, zinc, vitamin C, energy, protein, carbohydrate, and fat. Poor folic acid status was associated with low income and the deficiency was more common in rural areas, $20.1 \%$ compared to $14.7 \%$ in urban areas [72].

Moreover, underweight and short stature related to iodine deficiency and goiter as detected by palpitation, have been reported in Manisa region, Western Turkey [73]. Besides, a widespread iodine deficiency,marginal selenium levels have been reported for Turkey [74]. Overall nutritional status of minerals and vitamins is an understudied topic, which requires further investigation by the scientific community regarding the population in Turkey, in addition to weight status and health.

Table 4. Underweight prevalence (\%) in Turkey

Age 6-18 years

Age 18+ years

\begin{tabular}{lcccc}
\hline & Male & Female & Male & Female \\
\hline Overweight & $19.0 \%$ & $18.6 \%$ & $1.8 \%$ & $2.7 \%$ \\
\hline Source: Turkish Ministry of Health, $2010[33]$ & & & \\
\hline
\end{tabular}

\section{Concluding remarks}

Nowadays, in Turkey adolescents in particular are heavily influenced by the eating habits and health behavior of western societies, reflected for instance in the skipping of breakfast and frequent snacking of highly processed packaged foods [22]. Despite an international reputation for an elaborate cuisine, with regular and structured meals, this traditional eating pattern is declining over time due to changing lifestyles and more complex logistics.

As of recently, most Turkish adolescents appear to be of normal weight, while overweight and obesity co-occur with underweight (Tables 3 \& 4). Unlike overweight and obesity, it is not 
currently clear whether/how underweight constitutes a risk factor for CVD manifestation. Similar to studies and research presented herein, underweight was not regarded as a critical risk factor for CVD. It nonetheless constitutes an interesting observation from a nutritional and public health perspective and it cannot be excluded as a potentially influencing parameter as far as overall health status and particularly chronic disease risk are concerned.

Numerous approaches assessing dietary intake all seem to build consensus on the view that an overall dynamic shift towards westernized trends is underway in young populations in Turkey, particularly those in urban environments and of higher socioeconomic status [4, 33, 6163]. As Turkey is undergoing rapid urbanization these trends are expected to intensify. The fact that consistently higher education level and socioeconomic status are associated with child obesity and less favorable lipid profile, the opposite trend of what is observed in the West (USA and Europe), indicates the different nature of the nutritional problem in Turkey compared to the West. In Western societies the cost of fruits and vegetables often times makes these food choices less likely for disadvantaged populations, even though lack of knowledge is not the major determinant for different food choices. The populations of higher socioeconomic status possess both the knowledge and the resources to acquire the type of food that confers the healthiest outcomes. In Turkey we see for instance that despite low prices of fruits and vegetables (even adjusted for local purchasing power) these foods do not typically constitute the choices of children from high socioeconomic backgrounds. There seems to be a particular need in Turkey for nutrition education at this critical age, extended to families and especially mothers, regardless of weight and parental social/educational level as it is also highly probable that unhealthy eating habits may well be prevalent among normal weight adolescents also.

Adolescent underweight attributed to lower energy intakes, irregular eating patterns such as meal skipping, may well create a susceptible group of individuals for metabolic syndrome in adulthood. Altering energy intake and eating patterns overtime due to improved food access could prepare the ground for expressing features of metabolic syndrome in Turkish adults. Rapid urbanization and extensive, particularly youth relocation to cities may be a reason for changing dietary habits, increasing energy, salt and simple sugar intake, along with adopting lifestyle factors such as smoking and lack of physical activity, quick meals or meal-skipping. Moreover, moving away from a traditional and more religiousadherent family environment may lead to alcohol overconsumption as well, less access to cooked meals but more access to ready-made, massivelyproduced, highly-processed foods of questionable quality, preparation method and nutritional value (fast food, packaged food). While at large still a traditional society, eagerly although selectively adopting foreign trends (mainly Western) and influences regarding lifestyle, eating habits and declining cooking skills, can certainly contribute significantly to behaviors that promote malnutrition and exaggeration either towards the over- or the under- weight condition subsequently leading to lower level of good health and higher risk for chronic diseases, a trend already detected and reported.

\section{References}

1. Danaei G, Singh GM, Paciorek CJ, Lin JK, Cowan MJ, Finucane MM, Farzadfar F, Stevens GA, Riley LM, Lu Y, Rao M, Ezzati M; Global Burden of Metabolic Risk Factors of Chronic Diseases Collaborating Group. The global cardiovascular risk transition: associations of four metabolic risk factors with national income, urbanization, and Western diet in 1980 and 2008. Circulation. 2013 Apr 9;127(14):1493-502, 1502e1-8. DOI:

10.1161/CIRCULATIONAHA.113.001470.

2. Deaton C, Froelicher ES, Wu LH, Ho C, Shishani K, Jaarsma T. The global burden of cardiovascular disease. Eur J Cardiovasc Nurs. 2011 Jul;10 Suppl 2:S5-13. DOI: 10.1016/S1474-5151(11)00111-3.

3. Gersh BJ, Sliwa K, Mayosi BM, Yusuf S. 
Novel therapeutic concepts: the epidemic of cardiovascular disease in the developing world: global implications. Eur Heart J. 2010 Mar;31(6):642-8.

DOI: 10.1093/eurheartj/ehq030.

4. World Health Organization, 2013. Cardiovascular Diseases. http://www.who.int/mediacentre/factsheets/fs 317/en/.

5. Kelder SH, Peryy CL, Klepp KI, Lytle LL: Longitudinal tracking of adolescent smoking, physical activity and food choice behaviors. Am J Public Health 1994, 84:1121-1126. DOI: 10.2105/AJPH.84.7.1121.

6. Eriksson JG, Forsen T, Tuomilehto J, Osmond C, Barker DJ: Early growth and coronary heart disease in later life: longitudinal study. BMJ 2001, 322:949-953. doi: 10.1136/ bmj.322.7292.949.

7. Beaglehole R: Cardiovascular diseases in developing countries, an epidemic that can be prevented. BMJ 1992, 305:1170-1171. doi:10.1136/bmj.305.6863.1170.

8. Guo SS, Huang C, Demerath E, Towne B, Chumlea WC, Siervogel RM: Body mass index during childhood, adolescence and young adulthood in relation to adult overweight and adiposity: the Fels Longitudinal Study. Int J Obes Relat Metab Disord 2000, 24:1628-1635. DOI:10.1038/sj.ijo.0801461.

9. Ritchie SA, Connell JM.The link between abdominal obesity, metabolic syndrome and cardiovascular disease. Nutr Metab Cardiovasc Dis. 2007 May;17(4):319-26. DOI:10.1016/j.numecd.2006.07.005.

10. Tailor AM, Peeters PH, Norat T, Vineis P, Romaguera D. An update on the prevalence of the metabolic syndrome in children and adolescents. Int J Pediatr Obes. 2010 May 3;5(3):202-13.

DOI:10.3109/17477160903281079.

11. Juonala M, Viikari JS, Raitakari OT. Main findings from the prospective Cardiovascular Risk in Young Finns Study. Curr Opin Lipidol. $2013 \quad$ Feb;24(1):57-64. DOI: 10.1097/MOL.0b013e32835a7ed4.

12. Kaikkonen JE, Mikkilä V, Raitakari OT.Role of childhood food patterns on adult cardiovascular disease risk. Curr Atheroscler Rep. $2014 \quad$ Oct;16(10):443. DOI: 10.1007/s11883-014-0443-z.

13. Raitakari OT. Cardiovascular risk prediction in children and adolescents. Clin Biochem. 2014 Jun;47(9):722-3. DOI:10.1016/j.clinbiochem.2014.05.028.

14.Turkish Statistics Agency http://www.tuik.gov.tr/PreTablo.do?alt_id=10 $\underline{47}$.

15. Pekcan G. Food and nutrition policies: what's being done in Turkey. Public Health Nutr. 2006 Feb;9(1A):158-62. DOI: 10.1079/PHN2005939.

16. Sahingoz SA, Sanlier N. Compliance with Mediterranean Diet Quality Index (KIDMED) and nutrition knowledge levels in adolescents. A case study from Turkey. Appetite. 2011 Aug;57(1):272-7.

DOI:10.1016/j.appet.2011.05.307.

17. Ayranci U, Erenoglu N, Son O. Eating habits, lifestyle factors, and body weight status among Turkish private educational institution students. Nutrition. 2010 Jul-Aug;26(78):772-8. DOI:10.1016/j.nut.2009.07.007.

18. Besler HT, Buyuktuncer Z, Uyar MF. Consumer understanding and use of food and nutrition labeling in Turkey. J Nutr Educ Behav. $2012 \quad$ Nov-Dec;44(6):584-91. DOI:10.1016/j.jneb.2012.01.005.

19. Pekcan G, Karaagaoglu N. State of nutrition in Turkey. Nutr Health. 2000;14(1):41-52. DOI: $10.1177 / 026010600001400105$.

20. Baş M, Altan T, Dinçer D, Aran E, Kaya HG, Yüksek O. Determination of dietary habits as a risk factor of cardiovascular heart disease in Turkish adolescents. Eur J Nutr. 2005 Mar;44(3):174-82. DOI: 10.1007/s00394-004-0509-8.

21. Magnussen CG, Smith KJ, Juonala M. When to prevent cardiovascular disease? As early as possible: lessons from prospective cohorts beginning in childhood. Curr Opin Cardiol. $2013 \quad$ Sep;28(5):561-8. DOI: 10.1097/HCO.0b013e32836428f4.

22. Erenoglu N, Ayranci U, Son O. Eating habits reported by secondary school students in a city of west Turkey. Eat Behav. 2006 Nov;7(4):348-54. 
DOI:10.1016/j.eatbeh.2005.11.009.

23. Sur H, Kolotourou M, Dimitriou M, Kocaoglu B, Keskin Y, Hayran O, Manios Y. Biochemical and behavioral indices related to BMI in schoolchildren in urban Turkey. Prev Med. $2005 \quad$ Aug;41(2):614-21. DOI:10.1016/j.ypmed.2004.11.029.

24. Kukulu K, Sarvan S, Muslu L, Yirmibesoglu SG. Dietary habits, economic status, academic performance and body mass index in school children: a comparative study. J Child Health Care. 2010 Dec;14(4):355-66. DOI:10.1177/1367493510380079.

25. Akman M, Akan H, Izbirak G, Tanriöver Ö, Tilev SM, Yildiz A, Tektaş S, Vitrinel A, Hayran O. Eating patterns of Turkish adolescents: a cross-sectional survey. Nutr J. 2010 Dec 19;9:67. DOI:10.1186/1475-28919-67.

26. Sahingoz SA, Sanlier N. Compliance with Mediterranean Diet Quality Index (KIDMED) and nutrition knowledge levels in adolescents. A case study from Turkey. Appetite. 2011 Aug;57(1):272-7.

DOI:10.1016/j.appet.2011.05.307.

27. Acar Tek N, Yildiran H, Akbulut G, Bilici S, Koksal E, Gezmen Karadag M, Sanlier N. Evaluation of dietary quality of adolescents using Healthy Eating Index. Nutr Res Pract. 2011 Aug;5(4):322-8. DOI: 10.4162/nrp.2011.5.4.322.

28. Baş M, Kiziltan G. Relations among weight control behaviors and eating attitudes, social physique anxiety, and fruit and vegetable consumption in Turkish adolescents. Adolescence. 2007 Spring;42(165):167-78.

29. Lloyd LJ, Langley-Evans SC, McMullen S. Childhood obesity and risk of the adult metabolic syndrome: a systematic review. Int J Obes (Lond). 2012 Jan;36(1):1-11. DOI: $\underline{10.1038 / \text { ijo.2011.186. }}$

30. de Onis M1, Blössner M, Borghi E. Global prevalence and trends of overweight and obesity among preschool children. Am J Clin Nutr. $2010 \quad$ Nov;92(5):1257-64. DOI: $10.3945 /$ ajen.2010.29786.

31.Rome ES. Obesity prevention and treatment. Pediatr Rev. 2011 Sep;32(9):363-72; quiz 373. DOI: 10.1542/pir.32-9-363.
32. World Health Organization, 2012. Cardiovascular Diseases. http://www.who.int/mediacentre/factsheets/fs 317/en/.

33. Turkish Ministry of Health. http://www.saglik.gov.tr/EN/ana-sayfa/20/20141125.html.

34. Erem C, Hacihasanoglu A, Deger O, Kocak M, Topbas M. Prevalence of dyslipidemia and associated risk factors among Turkish adults: Trabzon lipid study. Endocrine. 2008 Aug-Dec;34(1-3):36-51. DOI: 10.1007/s12020-008-9100-Z.

35. Onat A. Risk factors and cardiovascular disease in Turkey. Atherosclerosis. 2001 May;156(1):1-10. DOI:10.1016/S00219150(01)00500-7.

36. Onat A, Uyarel H, Hergenç G, Karabulut A, Albayrak S, Can G. Determinants and definition of abdominal obesity as related to risk of diabetes, metabolic syndrome and coronary disease in Turkish men: a prospective cohort study. Atherosclerosis. 2007 Mar;191(1):182-90. DOI:10.1016/j.atherosclerosis.2006.03.012.

37. Onat A, Sari I, Hergenç G, Yazici M, Uyarel H, Can G, Sansoy V. Predictors of abdominal obesity and high susceptibility of cardiometabolic risk to its increments among Turkish women: a prospective populationbased study. Metabolism. 2007 Mar;56(3):348-56.

DOI:10.1016/j.metabol.2006.10.016.

38. Onat A, Ayhan E, Hergenç G, Can G, Barlan MM. Smoking inhibits visceral fat accumulation in Turkish women: relation of visceral fat and body fat mass to atherogenic dyslipidemia, inflammatory markers, insulin resistance, and blood pressure. Metabolism. 2009 Jul;58(7):963-70. DOI:10.1016/j.metabol.2009.02.029.

39. Agirbasli M, Cakir S, Ozme S, Ciliv G. Metabolic syndrome in Turkish children and adolescents. Metabolism. 2006 Aug;55(8):1002-6. DOI:10.1016/j.metabol.2006.03.009.

40. Nadeau KJ, Maahs DM, Daniels SR, Eckel RH. Childhood obesity and cardiovascular disease: links and prevention strategies. Nat 
Rev Cardiol. 2011 Jun 14;8(9):513-25. DOI:10.1038/nrcardio.2011.86.

41. Inanç BB, Sahin DS, Oğuzöncül AF, Bindak $\mathrm{R}$, Mungan F. Prevalence of obesity in elementary schools in mardin, South-eastern of Turkey: a preliminary study. Balkan Med J. 2012 Dec;29(4):424-30. DOI: 10.5152/balkanmedj.2012.051.

42. Sancak R, Dündar C, Totan M, Çakır M, Sunter T, Küçüködük S. The Prevalence and the Predisposing Factors of Obesity in Secondary and High School Students. J Exp Clin Med. 1999;16:19-24.

43. Akış N, Pala K, Irgıl E, Aydın N, Aksu H. Overweight and Obesity Among 6-14 Year Aged Schoolchildren at Six Elementary Schools in Orhangazi-Bursa. Uludag University Med J. 2003;29:17-20.

44. Gozu A. Prevalence of overweight and obesity among 6-15 year-aged at elementary schools in Mardin. Med Res J. 2007;5:31-5.

45. Semız S, Ozdemır OM, Ozdemir AS. The prevalence of obesity in childhood 6-15 years of age in Denizli. Pamukkkale Med J. 2008;1:1-4.

46. Süzek H, Arı Z, Uyanık B. The eating habits and prevalences of overweight and obesity in 6-15 years old school-children living in the villages of Muğla center. The New Journal of Medicine. 2010;27:22-8.

47. Turan S, Omar A, Berber M, Ozen A, Bereket A. Effect of socio-economical condition and age on prevalence of obesity. Proceedings of the IX. National Pediatric Endocrinology Congress. PP F-2. Malatya. 2004.

48. Krassas GE, Tsametis C, Baleki V, Constantinidis T, Unluhizarci K, Kurtoglu S, Kelestimur F. Balkan Group for the Study of Obesity. Prevalence of overweight and obesity among children and adolescents in Thessaloniki-Greece and Kayseri-Turkey. Pediatr Endocrinol Rev. 2004;1:460-464.

49. Oner N, Vatansever U, Sari A, Ekuklu E, Guzel A, Karasalihoglu S, Boris NW. Prevalence of underweight, overweight and obesity in Turkish adolescents. Swiss. Med Wkly. 2004;134:529-533.

50. Uckun-Kitapci A, Tezic T, Firat S, Sipahi T, Barrier R, Edwards LJ, Calikoglu AS.
Obesity and type 2 diabetes mellitus: a population-based study of adolescents. J Pediatr Endocrinol Metab. 2004;17:16331640.a

51. Simsek E, Akpinar S, Bahcebasi T, Senses DA, Kocabay K. The prevalence of overweight and obese children aged 6-17 years in the West Black Sea region of Turkey. Int J Clin Pract. 2008;62:1033-1038. DOI: $10.1111 / \mathrm{j} .1742-1241.2007 .01421 . x$.

52. Saglam H, Tarim O. Prevalence and correlates of obesity in schoolchildren from the city of Bursa, Turkey. J Clin Res Pediatr Endocrinol. 2008;1:80-88.

53. Kalkan-Ucar S, Dizdarer C, Darcan S, Korkmaz S, Ergudenler Y, Asilsoy S, Bilgili G, Ozcan T, Goksen Simsek D, Coker M. Prevalence of obesity and overweight among children in İzmir, Turkey: effects of nutritional and socio-economic factors. Obesity and Metabolism. 2009;5:99-106.

54. Discigil G, Tekin N, Soylemez A. Obesity in Turkish children and adolescents: prevalence and non-nutritional correlates in an urban sample. Child Care Health Dev. 2009;35:153-158. DOI: 10.1111/j.13652214.2008.00919.x.

55. Cizmecioglu FM, Etiler N, Hamzaoglu O, Hatun S. Prevalence of metabolic syndrome in schoolchildren and adolescents in Turkey: a population-based study. J Pediatr Endocrinol Metab. 2009;22:703-714. DOI: 10.1515/JPEM.2009.22.8.703.

56. Yuca AS, Yilmaz C, Cesur Y, Dogan M, Kaya A, Basaranoglu M. Prevalence of overweight and obesity in children and adolescents in eastern Turkey. J Clin Res Pediatr Endocrinol. 2010;2:159-163.

57. Pirincci E, Durmus B, Gundogdu C, Acik Y. Prevalence and risk factors of overweight and obesity among urban school children in Elazig city, Eastern Turkey, 2007. Ann Hum Biol. 2010;37:44-56. DOI: 10.3109/03014460903218984.

58. Turkkahraman D, Bircan I, Tosun O, Saka O. Prevalence and risk factors of obesity in school children in Antalya, Turkey. Saudi Med J. 2006;27:1028-1033.

59. Ercan S, Dallar YB, Önen S, Engiz Ö. 
Prevalence of obesity and associated risk factors among adolescents in Ankara, Turkey.J Clin Res Pediatr Endocrinol. 2012 Dec;4(4):204-7.

60. Directorate General of the Repoblic of Turkey Ministry of Health Studies: http://www.sagem.gov.tr/TBSA_Beslenme_Y ayini.pdf.

61. Manios Y, Dimitriou M, Moschonis G, Kocaoglu B, Sur H, Keskin Y, Hayran O. Cardiovascular disease risk factors among children of different socioeconomic status in Istanbul, Turkey: directions for public health and nutrition policy. Lipids Health Dis. 2004 Jun 4;3:11. DOI:10.1186/1476-511X-3-11.

62. Kocaoglu B, Moschonis G, Dimitriou M, Kolotourou M, Keskin Y, Sur H, Hayran O, Manios Y. Parental educational level and cardiovascular disease risk factors in schoolchildren in large urban areas of Turkey: directions for public health policy. BMC Public Health. 2005 Feb 4;5:13. DOI:10.1186/1471-2458-5-13.

63. Mahley RW, Arslan P, Pekcan G, Pépin GM, Ağaçdiken A, Karaağoğlu N, Rakicioğlu N, Nursal B, Dayanikli P, Palaoğlu KE, Bersot TP. Plasma lipids in Turkish children: impact of puberty, socioeconomic status, and nutrition on plasma cholesterol and HDL. J Lipid Res. 2001 Dec;42(12):1996-2006.

64. Garipagaoglu M, Budak N, Süt N, Akdikmen $\mathrm{O}$, Oner N, Bundak R. Obesity risk factors in Turkish children. J Pediatr Nurs. 2009 Aug;24(4):332-7.

DOI:10.1016/j.pedn.2008.04.003.

65. Dinç G, Saatli G, Baydur H, Ozcan C. Hypertension and overweight among Turkish adolescents in a city in Aegean region of Turkey: a strong relationship in a population with a relatively low prevalence of overweight. Anadolu Kardiyol Derg. 2009 Dec;9(6):450-6.

66. Nur N, Cetinkaya S, Yilmaz A, Ayvaz A, Bulut MO, Sümer H. Prevalence of hypertension among high school students in a middle Anatolian province of Turkey. J Health Popul Nutr. 2008 Mar;26(1):88-94.
67. Agirbasli M, Tanrikulu B, Arikan S, Izci E, Ozguven S, Besimoglu B, Ciliv G, MaraditKremers H. Trends in body mass index, blood pressure and parental smoking habits in middle socio-economic level Turkish adolescents. J Hum Hypertens. 2008 Jan;22(1):12-7. DOI:10.1038/sj.jhh.1002262.

68. Atabek ME, Pirgon O, Kurtoglu S. Prevalence of metabolic syndrome in obese Turkish children and adolescents. Diabetes Res Clin Pract. 2006 Jun;72(3):315-21. DOI:10.1016/j.diabres.2005.10.021.

69. Agirbasli M, Agaoglu NB, Ergonul O, Yagmur I, Aydogar H, Oneri T, Ozturk O. Comparison of anthropometric indices in predicting metabolic syndrome components in children. Metab Syndr Relat Disord. 2011 Dec;9(6):453-9. DOI:10.1089/met.2011.0018.

70. Keskin Y, Moschonis G, Dimitriou M, Sur H, Kocaoglu B, Hayran O, Manios Y. Prevalence of iron deficiency among schoolchildren of different socio-economic status in urban Turkey. Eur J Clin Nutr. 2005 Jan;59(1):64-71.

DOI:10.1038/sj.ejen.1602035.

71. Işık Balcı Y, Karabulut A, Gürses D, Ethem Çövüt I.Prevalence and Risk Factors of Anemia among Adolescents in Denizli, Turkey.Iran J Pediatr. 2012 Mar;22(1):77-81.

72. Oner N, Vatansever U, Garipagaoglu M, Karasalihoğlu S. Dietary intakes among Turkish adolescent girls. Nutr. Research. 2005 Apr;24(4):377-386. DOI:10.1016/j.nutres.2005.01.002.

73. Ersoy B, Günes HS, Gunay T, Yilmaz O, Kasirga E, Egemen A. Interaction of two public health problems in Turkish schoolchildren: nutritional deficiencies and goiter. Public Health Nutr. 2006 Dec;9(8):1001-6. DOI:10.1017/PHN2006983.

74. Hincal F.Trace elements in growth: iodine and selenium status of Turkish children. J Trace Elem Med Biol. 2007;21 Suppl 1:40-3. DOI:10.1016/j.jtemb.2007.09.012. 